\title{
Advanced Lending Operations and Credit Risk Assessment Using Purchase Order Information
}

\author{
Suguru Yamanaka \\ suguru.yamanaka@boj.or.jp
} Department

Papers in the Bank of Japan Working Paper Series are circulated in order to stimulate discussion and comments. Views expressed are those of authors and do not necessarily reflect those of the Bank.

If you have any comment or question on the working paper series, please contact each author. When making a copy or reproduction of the content for commercial purposes, please contact the Public Relations Department (post.prd8@boj.or.jp) at the Bank in advance to request permission. When making a copy or reproduction, the source, Bank of Japan Working Paper Series, should explicitly be credited. 


\title{
Advanced Lending Operations and Credit Risk Assessment Using Purchase Order Information *
}

\author{
Suguru Yamanaka ${ }^{\dagger}$
}

December 2016

\begin{abstract}
This paper proposes advanced lending operations and credit risk assessment using purchase order information from borrower firms. Purchase order information from a borrower firm is useful for financial institutions to evaluate the actual business conditions of the firm. This paper shows the application of purchase order information to lending operations and credit risk assessment, and reveals its effectiveness. First, we illustrate purchase order financing, which is the lending method backed by purchase order information from borrowers. With purchase order financing, firms that consistently receive purchase orders from credit-worthy firms can borrow money under more favorable lending terms than the usual lending terms based on the financial statements of the borrower firm. Second, we propose real-time credit risk monitoring of firms. Financial institutions can monitor the actual business conditions of borrower firms by evaluating the firm's asset value using purchase order information. A combination of traditional firm monitoring using financial statements and high-frequency monitoring using purchase order information enables financial institutions to assess the business conditions of borrower firms more precisely and efficiently. Then, with high-frequency data, financial institutions can give borrower firms appropriate support if necessary on a timely basis.
\end{abstract}

Keywords: Purchase order; Lending operations; Credit risk

\footnotetext{
* The author thanks Hidetoshi Nakagawa (Hitotsubashi University), the participants at the workshop of the Center for Advanced Financial Technology, Bank of Japan, on March 11, 2016, the participants at the mathematical finance session at the annual meetings of the Japan Society for Industrial and Applied Mathematics 2016, and the staff of the Bank of Japan for their useful comments. The author thanks Kojima Industries Corporation for providing data for analysis. The views expressed here are those of the author and do not necessarily reflect the official views of the Bank of Japan or its Financial System and Bank Examination Department.

${ }^{\dagger}$ Financial System and Bank Examination Department (suguru.yamanaka@boj.or.jp)
} 


\section{Introduction}

Information on commercial transactions, such as purchase order (PO) information, is considered useful for financial institutions to assess the business conditions of borrower firms. ${ }^{1}$ However, the use of $\mathrm{PO}$ information is not widespread among financial practice in Japan. One of the reasons is that there are no PO data collection systems which financial institutions are able to use. Another reason is that the effectiveness of using PO information are not clear. However, advancing information technology in finance, "FinTech", is promoting the use of PO information in financial businesses with the realization of an information system that collects information on commercial transactions, for example, the financial EDI (Electronic Data Interchange). Thus, this paper shows the usefulness of PO information in financial businesses, particularly for lending operations.

For traditional loan application screening, borrower firms are mainly evaluated using their financial statements which are made regulary, e.g. annualy. More precisely, financial institutions evaluate firms by their past financial statements, and lending approval depends on the existence of collateral. There are several problems with this traditional method of lending application judgment. First, financial statements, which should describe actual business conditions, may not describe them accurately, particularly in the case of non-listed small or medium-size firms. Second, because the financial statements represent static information that only describes firm statements at one point in time, financial institutions cannot recognize possible changes in a firm's condition when using only the financial statements. Third, as almost all financial institutions evaluate firms with similar method, the lending offers are likely to concentrate on the firms that is given high credit rating from their financial statements while others, such as startup firms, are likely to find it difficult to borrow the necessary amount of fund.

Financing based on commercial transaction information is expected to address the problems associated with traditional lending methods. ${ }^{2}$ This paper focuses on PO information and illustrates the advanced lending operations using PO information. PO information is provided by the potential borrower (seller) to the lender and shows the level of PO volume received from customers (buyer) indicating the projected business conditions of the borrower firm. Then, lenders can evaluate the potential borrower firm by their PO information. For example, if a firm receives consistent POs from credit-worthy firms, there is a strong likelihood that the firm will get proceeds of sales soon. In that case, backed by the PO information, financial institutions can lend to the firm under favorable lending terms. Another application of PO information is

\footnotetext{
${ }^{1}$ In this paper, commercial transactions indicate manufacturing, purchasing, shipments, and payment and settlement. PO information includes attributions of buyers, date of purchase order receipts, product attributions, PO amount, shipment date, and product prices.

2 One example of finance-based commercial transaction information is asset based lending (ABL). See Udell (2004) for details.
} 
real-time monitoring of the business conditions of the borrower firm. If the financial institutions obtain real-time PO information, they can immediately identify changes in the business conditions and credit quality of the borrower firm. Figure 1 summarizes the idea of advanced lending operations using PO information.
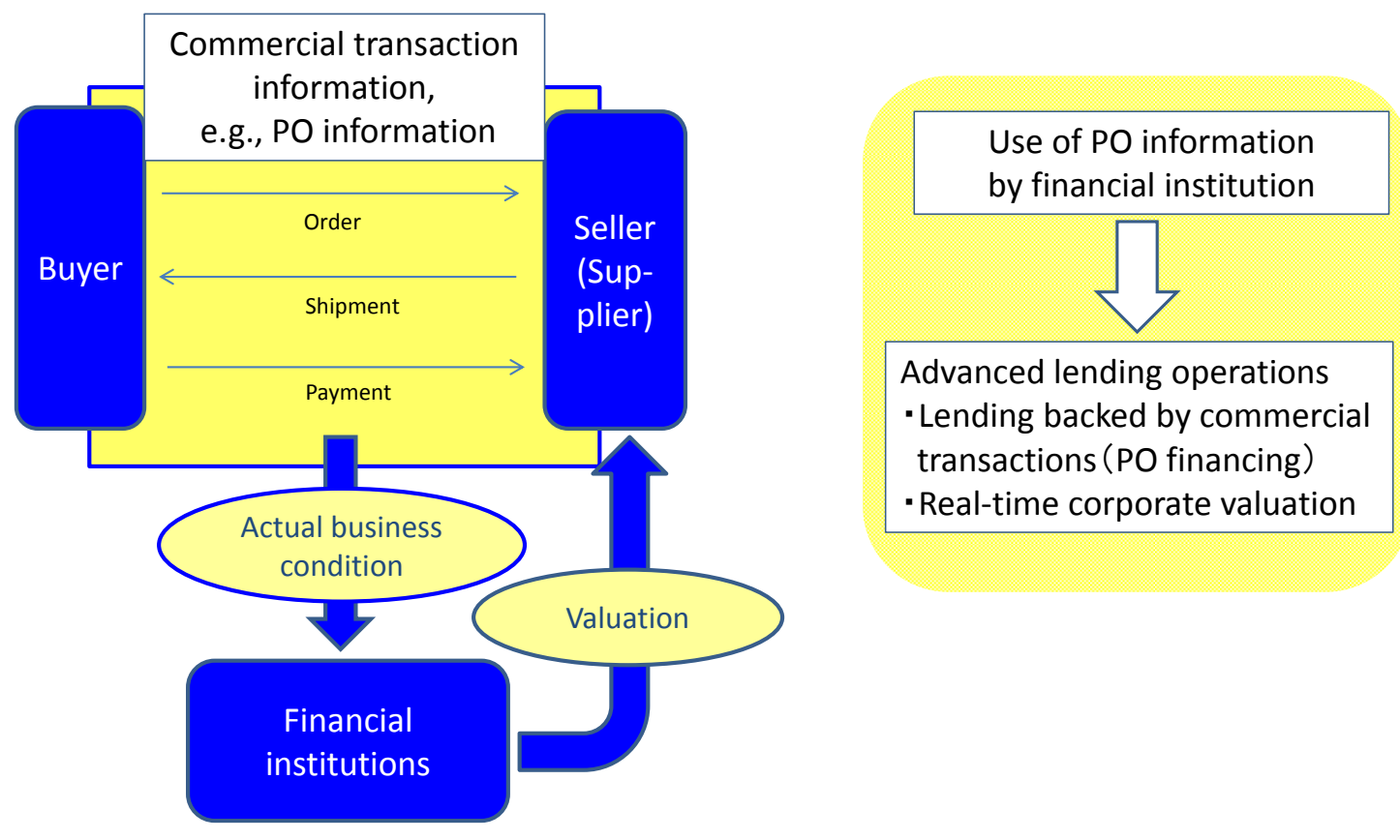

Fig. 1: Advanced lending operations using PO information

We address two specific subjects on advanced lending operations using PO information. The first subject is the lending backed by PO information called purchase order financing (PO financing). PO financing is a scheme under which a firm borrows from financial institutions when the firm receives a PO. Then, the firm repays the financial institution from the sales.

The second subject is the real-time valuation and monitoring of borrower firms, which provide information of business conditions. We propose a quantitative credit risk model using PO information and demonstrates real-time firm monitoring using the model. Typically, firm monitoring is exercised on a regular basis through the analysis of financial statements. These traditional monitoring methods do not provide a real-time snapshot of the changes in business conditions. In addition, traditional monitoring methods rely heavily on costly human resources and time. On the other hand, monitoring with PO information enables financial institutions to capture precise business conditions on a real-time basis, which is not the case when only financial statements are used. Moreover, a valuation system combined with automated systems for getting PO data and credit risk models using PO information can enhance effectiveness of monitoring. 
We demonstrate a case study that shows the effect of PO information on firm monitoring with real PO samples provided by Kojima Industries Corporation. ${ }^{3}$

This paper is organized as follows. Section 2 illustrates PO financing. Section 3 introduces real-time firm monitoring using PO information. Section 4 concludes. Appendix describes details of the quantitative credit risk model based on PO information, which is used for real-time firm monitoring illustrated in Section 3.

\section{PO financing}

In usual business activities, the receipt of a PO means that the firm is going to receive proceeds of sales soon. PO financing is the lending method that assumes repayment from the proceeds of sales.

For PO financing, a firm borrows from financial institutions when it receives a PO. Then, the borrower firm repays the financial institutions from the proceeds of sales. Figure 2-(a) illustrates the structure of PO financing. The structure of PO financing is the following: 1. Receipt of PO. 2. Funding provided by financial institutions. 3 . Shipment of ordered products. 4. Collection of proceeds of sales. 5. Repayment to financial institutions from proceeds of sales.

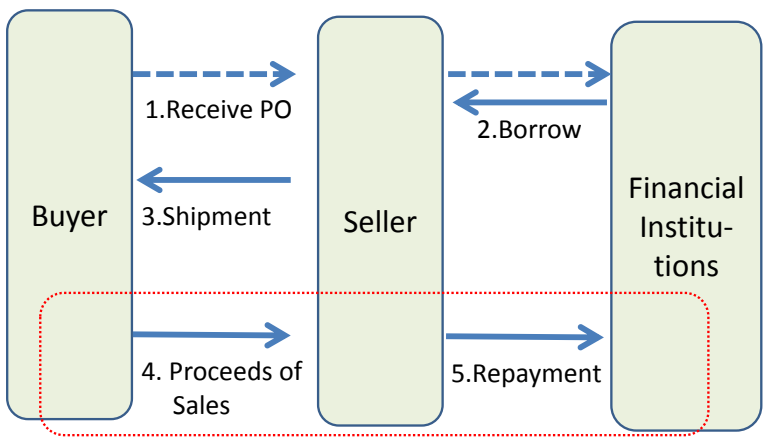

(a) PO financing

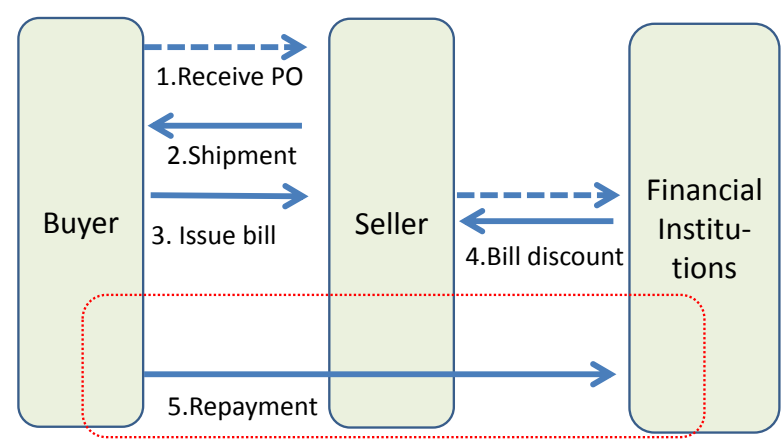

(b) Discounted billing

Fig. 2: Lending backed by PO information

PO financing has been used to finance operating capital, particularly when the period between receiving orders and collecting proceeds of sales is long. Suppose

3 The data is non-public informaion. Kojima Industries Corporation has been tackling empirical experiments on advanced accounting works using financial EDI. The firm has been expecting advanced financing using PO information, and they are cooperative in providing their PO data to us. Kunihiko Kaneko, who is a director of the firm, joined the workshop on "finance based on commercial flows", hosted by the Center for Advanced Financial Technology, Financial System and Bank Examination Department, Bank of Japan. Kaneko made presentation on the empirical experiments coducted by the firm on financial EDI . 
that the seller (borrower firm) completes the shipment of ordered products, the main risk to which financial institutions are exposed is the default risk of buyer. Another example of a financing method in which the main risk is the default risk of buyer is discounted billing (see Figure 2-(b).)

Now, we illustrate the effectiveness of PO financing with the sample data of PO volume provided by Kojima Industries Corporation. Kojima Industries Corporation manufactures interior and exterior automobile components. The capital of the firm is 450 million yen and annual sales are 151.1 billion yen. ${ }^{4}$ The main customers (buyers) of the firm are auto manufacturers such as Toyota Motor Company, Toyota Auto Body Company, Toyota Motor East Japan Incorporated, Hino Motors, and Daihatsu Motor Company. The cumulative PO amount between January 2011 and December 2013 shows that approximately $90 \%$ of PO volume is ordered by buyers with AA credit rating. ${ }^{5}$ Therefore, using PO financing, Kojima Industries Corporation can borrow capital up to $90 \%$ of its PO volume with AA credit rating quality lending terms.

PO financing is useful especially for small or medium-size firms. Although a firm is considered small, if it receives POs from high credit-quality buyers, the firm can borrow with favorable terms backed by the high credit quality of its buyers.

\section{Quantitative credit risk monitoring based on PO information}

This section provides an automatic quantitative monitoring method with a quantitative credit risk model using PO data. Particularly, we present a credit risk model based on PO information and demonstrate a case study that shows the effectiveness of the model.

In our model, the asset value of the borrower firm is derived from its PO information, and the borrower defaults when the asset value goes below the debt value. Figure 3 shows the structure of our model. First, (a) we construct a time-series model of PO volume transition for each buyer. Here, the correlation of PO volumes among corresponding buyers, which is caused by changes in business circumstances, are considered in the PO volume time-series model. In addition, to capture the risk of losing POs, (b) default models of buyers with default correlations among buyers are considered. Particularly, we employ the default correlation model for which a buyer defaults when the credit quality hits the default barrier, and the transitions of credit quality of buyers are correlated. Then, (c) proceeds of sales are calculated by the sum of the POs with a time lag between receiving POs and collecting proceeds of

\footnotetext{
4 The data source is the Kojima Industries Corporation website (http://www.kojima-tns.co.jp/) as of August 29, 2016.

${ }^{5}$ Credit ratings are given by R\&I (Rating and Investment Information, Inc.) and JCR (Japan Credit Rating Agency, Ltd.), which are famous rating institutions in Japan. We ignore the notches of credit ratings (e.g. + and - ) through this paper.
} 
sales. If a buyer defaults before collecting sales, the firm receives only the recovery which is a part of the PO amount. Next, (d) we calculate the cost of producing and supplying products. Then, we obtain profits or losses from the difference between the sales and the costs. In addition, we adjust profits or losses by adding calculated impairment losses. Finally, we renew the asset value by adding obtained profits and losses to the previous asset value. If there are losses, the asset value is reduced. The supplier defaults when the asset value falls below the debt value. See Appendix for the model details.

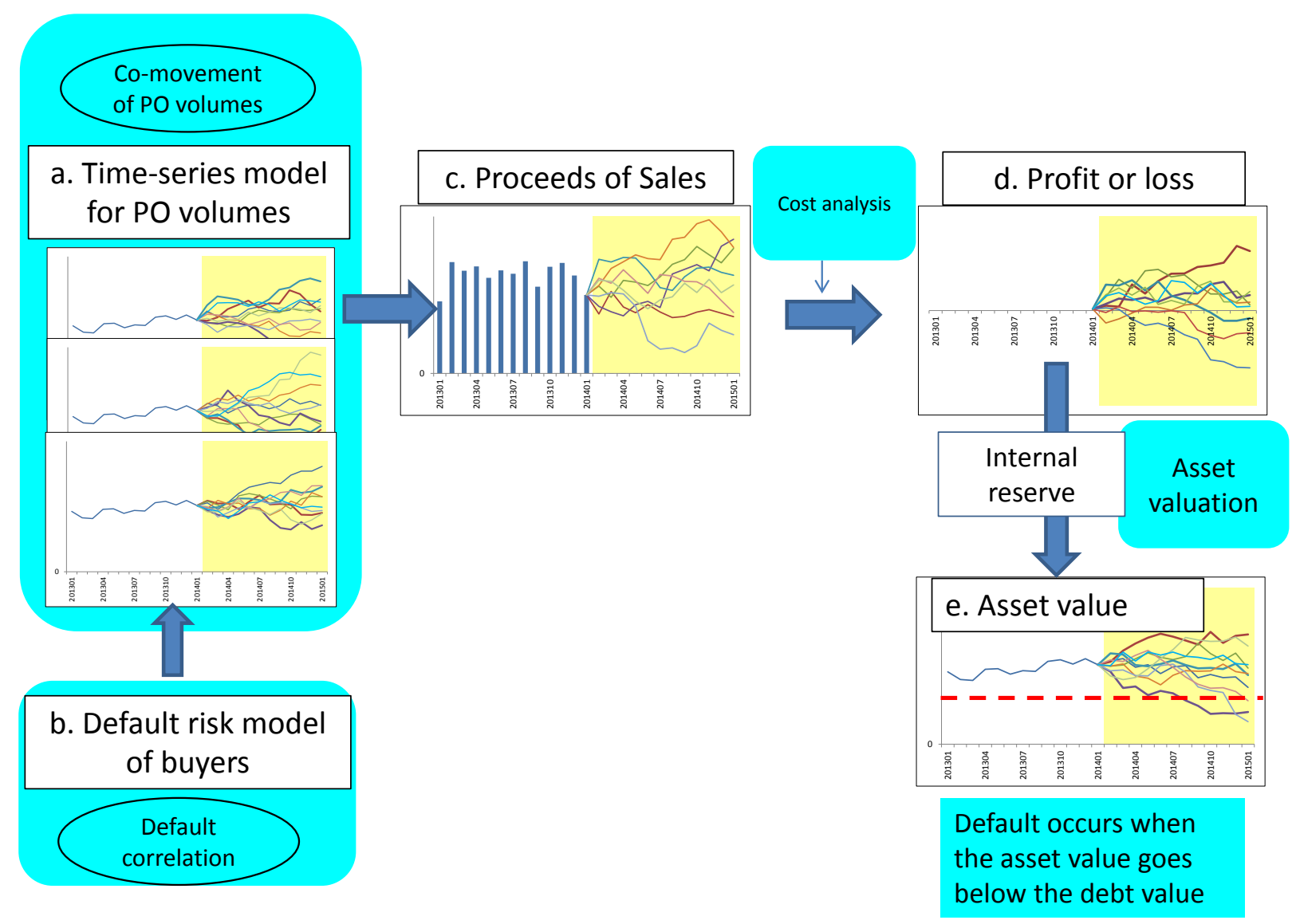

Fig. 3: Overview of the credit risk model based on PO information

The sample data for the case study are the historical PO records of Kojima Industries Corporation. The sample data are the monthly PO records from January 2011 to December 2014. Figure 4 shows the transition of monthly PO volumes in our samples. We recognize seasonality in PO volumes, for example, there is a relative decrease in PO volume every August and December. To handle the seasonality of PO volumes, we employ an autoregressive-type model of the $\mathrm{PO}$ volume ratio, which is calculated as the ratio of the PO volume to the PO volume of the same month in the 
previous year.

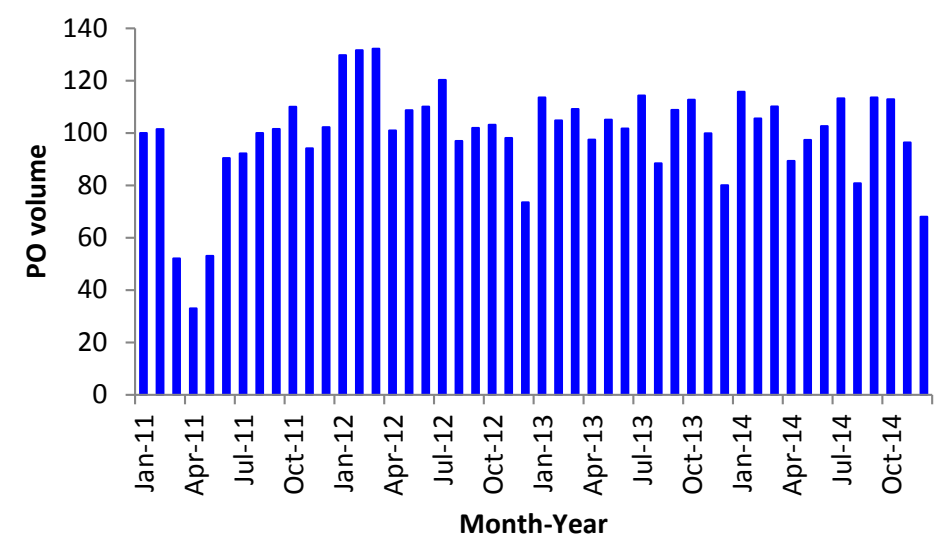

Note: The plotted values are standardized monthly PO volumes, setting the value of January 2011 as 100 .

Fig. 4: Transition of monthly PO volumes in our sample PO data

We provide numerical examples that show the influence of changes in POs and the credit quality of buyers on the probabilities of default (PDs) of Kojima Industrial Corporation. Using sample data for January 2011 to December 2013, we estimated model parameters and calculated one-year forward PDs of the firm for every month in 2014. In addition to calculating PDs under the realized PO scenario on PO volumes and credit qualities of buyers, we calculated PDs under stressed PO scenarios in which the credit rating of buyers declines.

Figure 5 shows the estimated PDs under the realized PO scenario. The level of estimated PDs is quite low, reflecting the high credit quality (low default risk) of the buyers and the stability of the PO volume. In addition, we recognize in Figure 5 that the estimated PDs increase reflecting the decrease in the PO volumes.

Figure 6 shows estimated PDs under the stressed PO scenarios in which the credit rating of buyers decline in May 2014. Figure 6 shows that the PD of Kojima Industries Corporation increases reflecting the lower credit ratings of buyers.

These results show that credit risk modeling based on PO information enables financial institutions to monitor the credit risk affected by change in business conditions of the borrower firms, such as PO volumes and the credit quality of buyers, on a realtime basis. This real-time monitoring of borrower firms represents advanced default prediction in lending operations and reduces the costs associated with traditional monitoring methods, which require substantial human resources and time.

Real-time credit risk monitoring of listed firms is typically conducted with structural credit risk models using their market stock prices. However, the monitoring method is not applicable to the monitoring of unlisted firms whose stock values are usually non-observed. On the other hand, credit risk monitoring using PO information can be applied to both listed and unlisted firms. 


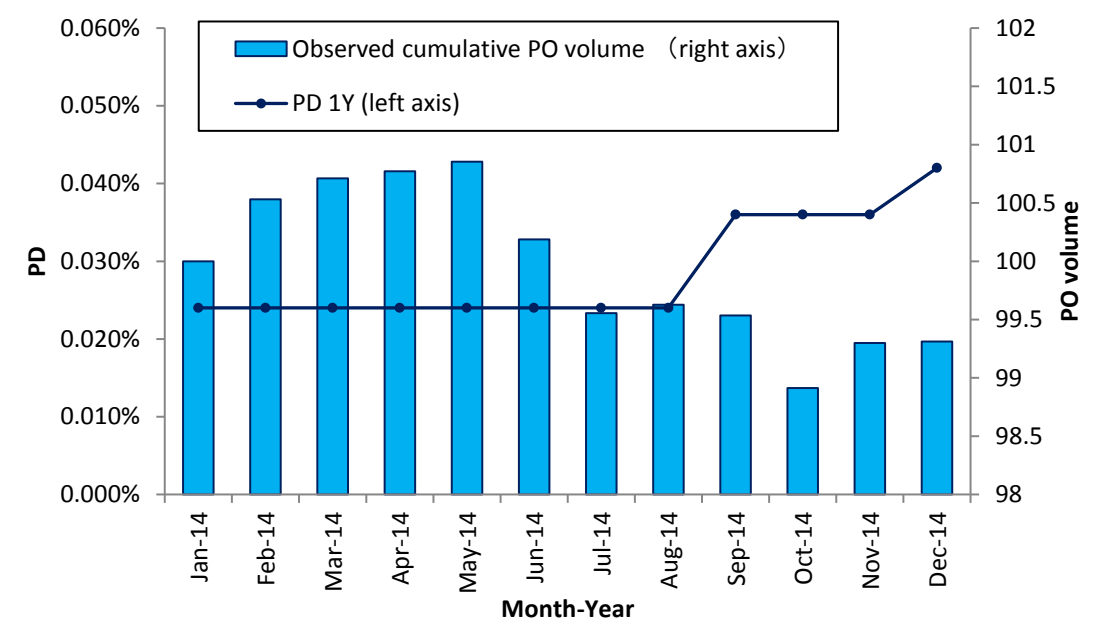

Note: The plotted cumulative one-year PO volumes are standardized by setting the cumulative one-year volume on January 2011 as 100.

Fig. 5: Estimated one-year PDs (solid line) of Kojima Industries Corporation and cumulative one-year PO volumes observed for each month (bar plots)

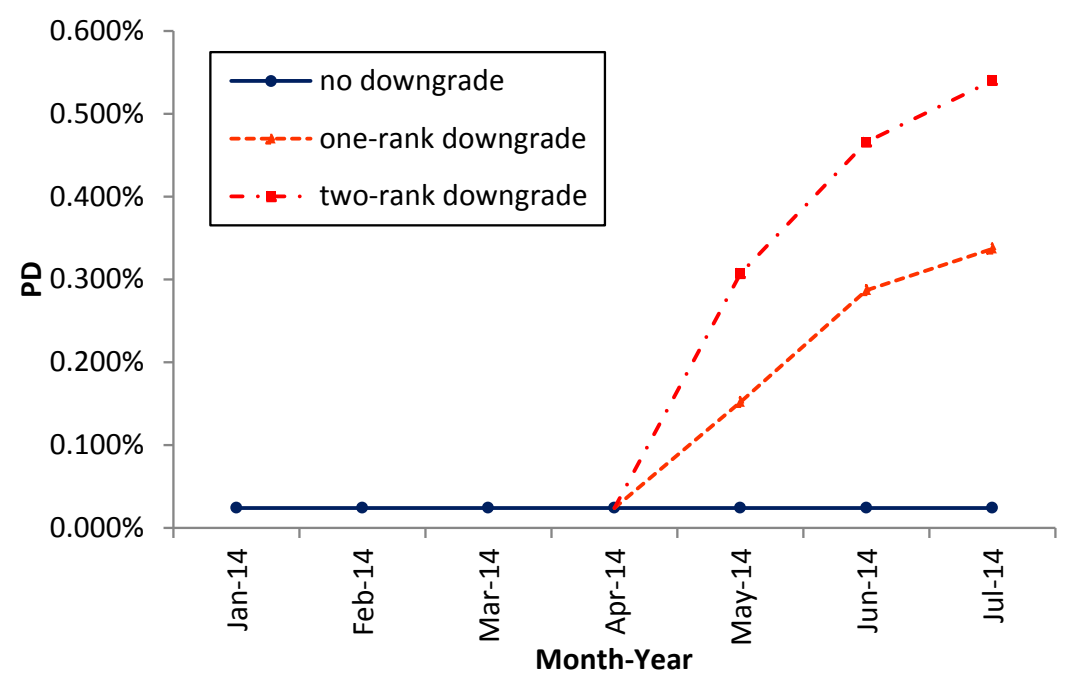

Note: Downgrades occur simultaneously in May 2014 in the stressed scenarios. The first scenario (dotted line with triangles) shows one-rank downgrade of the customers, and the second scenario (break line with boxes) shows two-rank downgrades of the customers.

Fig. 6: Estimated one-year PDs under scenarios where customers are downgraded 


\section{Conclusion}

This paper illustrated the advanced lending operations using PO information. First, we explained PO financing, which is the lending method backed by PO information. With PO financing, financial institutions can finance firms that have low credit quality and cannot get money without enough collateral. From another perspective, PO financing enables the firm with the high credit quality of their customers (buyers) to finance with favorable terms. For small, medium-size, and startup firms, the lending terms using PO financing would be better than the lending terms backed by only the financial statements.

Second, we proposed a quantitative credit risk model based on PO information and showed a case study with real-time monitoring of a firm's business conditions using the model. The results of the case study reveal the effectiveness of using PO information to monitor the credit risks of borrower firms. The method of obtaining PDs proposed in this paper can reduce the cost of monitoring borrower firms. If borrower firms supply PO information to financial institutions regularly, the borrower firms could be offered appropriate business support from financial institutions on a timely basis.

The advantages of using PO information for lending operations can increase the market competitiveness of the supply chain. That is, PO financing and firm monitoring using PO information lead to reduction in the financial costs of the borrower firm, which is a supplier in the supply chain, and this method reduces product prices. This cost reduction for buyers enables them to become more cost competitive. This then leads to sales growth and financial improvements for the buyers. Such improvements in a buyer's condition create a virtuous cycle of improvements in the supply chain. ${ }^{6}$

To realize the advanced lending operations and receive the benefits of PO information use, PO data collection systems, such as financial EDI, are required. The discussion on the implementation of financial EDI is ongoing in Japan. After realization of financial EDI, PO information will be used widely in the lending industry and also for other financial services. ${ }^{7}$

\section{Appendix Structural credit risk model based on PO data}

Here, we provide details on the credit risk model based on the PO data introduced in Section 3.

In our model, we obtain the asset value of the borrower firm from PO volume; then, the default occurs when the asset value falls below the debt value. Because the structure of default occurrences is explicitly modeled with the level of asset values, our model is a type of structural credit risk model. In previous works on structural credit risk models, the stochastic process of asset values is modeled directly (e.g., Merton

\footnotetext{
${ }^{6}$ Introducing financial EDI will be more effective for cost reductions.

7 In addition, rules and regulation on data usage, standardization of data formats and data sharing schemes among financial institutions are required for widespread use of PO data.
} 
1974) or obtained by aggregating future earnings (e.g., Goldstein, Ju, and Leland 2001, Genser 2006). On the other hand, we model PO volume transition first; then, the earnings and asset value are generated by the PO volume in our modeling framework. One of the advantages of our model is that we reflect the business conditions of the borrower firm, such as trends in PO volumes and the credit quality of buyers in the credit risk assessment.

\section{A. Modeling framework}

This section provides a structural framework for credit risk modeling based on PO information. We provide a simple modeling framework that shows the steps to derive asset value from PO information. Therefore, our model is simpler than the actual practical processes of generating firm assets from a PO.

The steps are the following:

1. Introduce a stochastic process for PO volumes

2. Calculate proceeds of sales

3. Calculate ordinary cash flows (excluding sales)

4. Calculate ordinary profits and losses

5. Calculate impairment losses

6. Calculate net earnings

7. Renew asset value

8. Define default

1. Introduce a stochastic process for PO volumes We model uncertainty in the economy on a filtered complete probability space $\left(\Omega, \mathcal{F},\left\{\mathcal{F}_{t}\right\}_{t \in \mathcal{T}}, \mathbb{P}\right)$ where $\left\{\mathcal{F}_{t}\right\}_{t \in \mathcal{T}}$ is a complete filtration with discrete time space $\mathcal{T}=\{0,1,2, \cdots, \infty\}$, and $\mathbb{P}$ is the physical probability measure. The target firm of credit risk assessment is the seller side of POs. We denote by $\mathcal{I}=\{1,2,3 \cdots, I\}$ the set of the corresponding buyer. PO volumes ordered by buyer $i \in \mathcal{I}$ are denoted by $\left\{O_{t}^{i}\right\}_{t \in \mathcal{T}}$, which is an $\left\{\mathcal{F}_{t}\right\}$-adopted stochastic process.

- 2. Calculate proceeds of sales Next, we calculate proceeds of sales obtained from associated $\mathrm{PO}$ volumes. We assume that the firm receives proceeds of sales amounting to $\mathrm{PO}$ volumes after some time lags if there are no problems with product delivery and sales collection. If there are canceled POs or buyer defaults before sales collections, cash below the PO amount is collected by cancellation charges and recovery given default. Thus, proceeds of sales at time $t$ are given by

$$
S_{t}=\sum_{i=1}^{I}\left(O_{t-h}^{i} 1_{\left\{t<T_{i}\right\}}+\left(1-L G D^{i}\right) O_{t-h}^{i} 1_{\left\{t \geq T_{i}\right\}}\right),
$$


where $\left\{\mathcal{F}_{t}\right\}$-stopping time $T_{i}$ indicates the default time of buyer $i$, and constant $h \geq 0$ is the time-lag between the arrival of the POs and collection of proceeds of sales. ${ }^{8}$ Constant $L G D^{i}$ is the rate of loss given default when the POs of buyer $i$ are canceled or buyer $i$ defaults.

3. Calculate ordinary cash flows (excluding sales) To obtain ordinary profits and losses, we introduce ordinary cash flows excluding proceeds of sales. One of the main components of ordinary cash flows is production costs associated with received POs. Thus, it is natural to assume that production costs are a function of PO volumes:

$$
C_{t}=f\left(\left\{O_{t-g}^{i}\right\}_{i \in \mathcal{I}}\right) .
$$

Here, function $f: \mathbb{R}^{I} \rightarrow \mathbb{R}$ is a cost function, and constant $g$ is the time lag between PO arrival and corresponding cost defrayment. ${ }^{9}$

4. Calculate ordinary profits and losses Cumulative ordinary profits and losses at time $\mathrm{t}$ are obtained by the difference in proceeds of sales and ordinary cash flows excluding proceeds of sales:

$$
P_{t}=\sum_{s=0}^{t}\left(S_{s}-C_{s}\right) .
$$

6. Calculate impairment losses In our model, impairment losses are introduced to recognize losses caused by future decrease in PO volumes. Accumulated impairment losses are the difference between the present value of operating earnings calculated at the initial time and time $t$ :

$$
I_{t}=\min \left(\tilde{V}_{t}-\tilde{V}_{0}, 0\right) .
$$

$\tilde{V}_{t}$ is the net present value of operating earnings at time $t$. $\tilde{V}_{t}$ is obtained as follows:

$$
\tilde{V}_{t}=\sum_{s=t}^{\infty} \mathbb{E}^{\mathbb{P}}\left[\frac{\tilde{P}_{s}}{(1+r)^{s-t}} \mid \mathcal{F}_{t}\right] .
$$

Here, constant $r$ is the firm's weighted average cost of capital (WACC). $\mathbb{E}^{\mathbb{P}}\left[\cdot \mid \mathcal{F}_{t}\right]$ is the $\mathcal{F}_{t}$-conditional expectation, and $\tilde{P}_{t}$ denotes operating earnings. Operating earnings are given by

$$
\tilde{P}_{t}=S_{t}-\tilde{C}_{t}
$$

where operating costs are

$$
\tilde{C}_{t}=\tilde{f}\left(\left\{O_{t-g}^{i}\right\}_{i \in \mathcal{I}}\right)
$$

with operating cost function $\tilde{f}: \mathbb{R}^{i} \rightarrow \mathbb{R}^{+}$.

8 The time lag between the arrival of the PO and the realization of sales is dependent on products and seasons. However, we set the time lag constant for simplicity.

${ }^{9}$ Negative (positive) value implies cash in (out). 
6. Calculate net earnings Earnings before tax (EBT) are obtained by adding ordinary profits and losses and impairment losses:

$$
E B T_{t}=P_{t}+I_{t}
$$

Then, the net earnings are obtained by adjusting tax payments to EBT:

$$
E_{t}=E B T_{t} 1_{\left\{E B T_{t}<0\right\}}+(1-G) E B T_{t} 1_{\left\{E B T_{t} \geq 0\right\}} .
$$

Here, the constant $G$ denotes the corporate tax rate.

च. Renew asset value We assume that there are no dividends to the shareholders, and net earnings are held as internal reserves. Then, the asset value at time $t$ is obtained by summing initial asset value $V_{0}$ and cumulative net earnings $E_{t}$ :

$$
V_{t}=V_{0}+E_{t}
$$

8. Define default The firm defaults when the asset value goes below the debt value. That is, the net asset value of the firm goes below zero. The net asset value $H_{t}$ is obtained by $H_{t}=V_{t}-D_{t}$, with debt value $D_{t}$. Then, the default time is

$$
\tau=\inf \left\{t \in \mathcal{T} \backslash\{0\} \mid H_{t}<0\right\} .
$$

\section{B. Case study settings}

Here, we introduce an empirical model for our case study, which is constructed under the provided framework in Appendix A. In addition, we illustrate the settings of the case study.

1. The details of the model employed for the case study

Now, we illustrate the formulation of our empirical model.

The buyers of Kojima Industries Corporation, such as Toyota Motor Company, belong to the automotive sector. As this example, when buyers belong to the same industrial sector, the PO volumes of each buyer tend to co-move with changes in business conditions. Thus, we suppose that the model can capture such co-movements of PO volumes. In addition, there is default correlations among buyers; therefore, we take into account them in our model.

- Modeling PO volumes We suppose monthly observed PO sample data for our case study. Then, the unit of time space $\mathcal{T}$ is one month. The data of monthly PO volume often have seasonal effects. To handle seasonal effects, we model the one-year difference of $\log$-PO volumes $R_{t}^{i}=\log \left(O_{t}^{i}\right)-\log \left(O_{t-12}^{i}\right)$. We employ the time-series model of $R_{t}^{i}$ described as follows:

$$
R_{t}^{i}=\alpha_{i}+\beta_{i} R_{t-1}^{i}+\sigma_{i}\left(\rho_{i} W_{t}+\sqrt{1-\rho_{i}^{2}} \epsilon_{i, t}\right)
$$


Here, $W_{t} \sim N(0,1), \epsilon_{i, t} \sim N(0,1)$ and these random variables are independent of time, where $N(m, v)$ is normal distribution with mean $m$ and variance $v$.

This model captures the correlation of $\mathrm{PO}$ volumes by common factor $W_{t}$, and the strength of the correlation is specified by the factor loading $\left\{\rho_{i}\right\}$. Idiosyncratic risks are captured by $\epsilon_{i, t}$.

The model estimation procedures we employed are the following. First, we estimate parameters $\left\{\alpha_{i}, \beta_{i}, \sigma_{i}\right\}$ by the following AR (Auto-Regressive) model

$$
R_{t}^{i}=\alpha_{i}+\beta_{i} R_{t-1}^{i}+\bar{\epsilon}_{i, t}, \quad \bar{\epsilon}_{i, t} \sim N\left(0, \sigma_{i}^{2}\right)
$$

with the observed one-year difference of log-PO volumes. Then, we estimate $\rho_{i}$ with obtained residuals $\bar{\epsilon}_{i, t}$. Here, we calculate the sample residual correlation matrix $\left\{\hat{\rho}_{i j}\right\}$ and obtain estimated parameters by minimizing the sum of square difference $\sum_{i=1}^{I} \sum_{j=1}^{i-1}\left(\rho_{i} \rho_{j}-\hat{\rho}_{i j}\right)^{2}$.

We model the POs of the buyers that are ranked in the top nine PO volumes $(i=1,2, \cdots 9)$. The sum of the top nine PO volumes is accounting for approximately $96 \%$ of all PO volumes. ${ }^{10}$ In addition, we model the aggregated remainder $(i=10)$. Thus, the number of buyers in the case study is $I=10$. The default risk of most of the buyers is relatively low because the range of their credit ratings is $\mathrm{AA}+\sim \mathrm{A}-$.

The estimated parameters of the PO model are described in Table B-1. Because most of the estimated values of auto-regressive coefficients $\left\{\beta_{i}\right\}$ are positive, we recognize the existence of PO trends in our sample data. The p-values of the Ljung-Box test show that there is no significant auto-correlation in the residuals, and the model is not rejected. ${ }^{11}$

Referring to the estimated values of factor loading $\rho_{i}$ in Table B-1, the estimates of correlation between any two buyers are over 0.4 calculating PO volume correlation between buyer $i$ and $j$ by $\rho_{i} \rho_{j}$. This implies that there are pairs of buyers who are highly correlated on POs in our samples.

PO volumes $\left\{O_{t}^{i}\right\}_{t \in \mathcal{T}}$ are obtained from $\left\{R_{t}^{i}\right\}$ as

$$
O_{t}^{i}=\left\{O_{t-12}^{i} \times \exp \left(R_{t}^{i}\right)\right\} 1_{\left\{t \leq T_{i}\right\}} .
$$

Here, $T_{i}$ is the time to break off business connections with buyer $i$. We assume the break-off of business connections occurs only when the buyer defaults. Then, $T_{i}$ is the same to the default time of buyer $i$.

Proceeds of sales are calculated with equation (1). We set the value of $L G D^{i}$ conservatively as $L G D^{i}=1$. The time lag between the order and collection of sales is set to two months $(h=2)$.

10 This ratio is obtained with the cumulative PO volumes from January 2011 to December 2013.

${ }^{11}$ In addition, we execute in-sample and out-of-sample tests for the time-series of the one-year difference of log-PO volumes. Here, we conduct the Kolmogorov-Smirnov (K-S) test, which tests goodness of fit of a realized series of residuals and associated distribution $N(0,1)$. From the K-S test, we confirm that the amount of PO volumes of the buyer that are not rejected under a $1 \%$ significant level is $100 \%$ for in-sample and $83.4 \%$ for the out-of-sample tests. The in-sample span is January 2012 to December 2013. The out-of-sample span is January 2014 to December 2014. 
Table. B-1 : Estimated parameter values of the model of one-year difference of log-PO

\begin{tabular}{lccccc}
\hline$i$ & 1 & 2 & 3 & 4 & 5 \\
\hline$\alpha_{i}$ & -0.039 & -0.047 & 0.006 & 0.159 & -0.013 \\
$\beta_{i}$ & 0.594 & 0.881 & 0.006 & 0.366 & 0.342 \\
$\sigma_{i}^{2}$ & 0.005 & 0.013 & 0.006 & 0.018 & 0.008 \\
$\rho_{i}$ & 0.970 & 0.883 & 0.733 & 0.349 & 0.338 \\
\hline p-value & 0.694 & 0.796 & 0.999 & 0.732 & 0.999 \\
\hline
\end{tabular}

\begin{tabular}{lccccc}
\hline$i$ & 6 & 7 & 8 & 9 & 10 \\
\hline$\alpha_{i}$ & 0.131 & 0.041 & 0.087 & -0.116 & -0.436 \\
$\beta_{i}$ & 0.257 & -0.243 & 0.756 & 0.073 & 0.624 \\
$\sigma_{i}^{2}$ & 0.013 & 0.065 & 0.019 & 0.011 & 0.090 \\
$\rho_{i}$ & 0.677 & 0.537 & 0.754 & 0.260 & 0.267 \\
\hline p-value & 0.793 & 0.754 & 0.341 & 0.961 & 0.583 \\
\hline
\end{tabular}

Note: p-values are obtained with the Ljung-Box test.

Default model for buyers Buyer defaults are modeled with a Merton-type one-factor Gaussian-copula model. The probability of default until time $t+1$, under the condition that buyer $i$ survives at least until time $t$, is obtained as the probability that the credit quality $X^{i}$ goes below default barrier $Q^{i}$. That is, the probability of default of buyer $i$ is $P\left(X^{i}<Q^{i}\right)$. Credit quality $X^{i}$ is given by

$$
\begin{aligned}
& X^{i}=\tilde{\rho}_{i} \tilde{W}+\sqrt{1-\tilde{\rho}_{i}^{2}} \tilde{\epsilon}_{i}, \\
& \tilde{W} \sim N(0,1), \tilde{\epsilon}_{i} \sim N(0,1)
\end{aligned}
$$

and these random variables are independent of time. Then, the probability of default of buyer $i$ is

$$
\mathbb{P}\left(X^{i}<Q^{i}\right)=\Phi\left(Q^{i}\right)
$$

where $\Phi(\cdot)$ is the cumulative normal distribution. The default correlation among buyers is captured by common factor $\tilde{W}$, and the strength of default correlation is specified by $\tilde{\rho}$.

Default barriers $Q^{i}$ are estimated according to eq.(7) with the historical probabilities of defaults of the associated credit rating of buyer $i$. For no-rated buyers, we assume the ratings as BBB.

We estimate default correlations among buyers with the stock price data for the buyers. For non-listed buyers, we employ TOPIX sector indices of the corresponding sector and consider them the stock data for the buyer. We estimate parameters by minimizing the sum of the square difference between the historical correlation matrix 
of stock prices and the correlation matrix obtained by factor loadings. ${ }^{12}$ Estimates of factor loading are shown in Table B-2.

Table. B-2 : Estimated value of default correlation parameter

\begin{tabular}{cccccc}
\hline$i$ & 1 & 2 & 3 & 4 & 5 \\
\hline$\tilde{\rho}_{i}$ & 0.849 & 0.877 & 0.877 & 0.825 & 0.836 \\
\hline \multicolumn{6}{c}{} \\
\hline$i$ & 6 & 7 & 8 & 9 & 10 \\
\hline$\tilde{\rho}_{i}$ & 0.711 & 0.715 & 0.902 & 0.827 & 0.877 \\
\hline
\end{tabular}

Drdinary cash flow model We simply assume that the function of ordinary cash flow excluding proceeds of sales is given by the linear function

$$
f\left(\left\{O_{t-g}^{i}\right\}_{i \in \mathcal{I}}\right):=a \sum_{i=1}^{I} O_{t-g}^{i} 1_{\left\{t<T_{i}\right\}}+b .
$$

To estimate the parameters of the above function, we use the historical annual PO volumes and related items from the firm profit and loss statements $(\mathrm{P} / \mathrm{L})$. We calculate realized ordinary cash flow excluding proceeds of sales as the sum of operating costs and non-operating profits and losses. Then, we execute linear regression of the realized ordinary cash flow except sales by employing annual sales as explanatory variables. ${ }^{13}$ The coefficients obtained by linear regression are annually based values, and we transform them into the monthly based values. The obtained coefficients of ordinary cash flow function are $a=0.905$ and $b=7.83 \times 10^{8} .{ }^{14}$

With the estimated ordinary cash flow function, according to eq.(2), we obtain the revenues for ordinary cash flow except sales. Here, we tentatively set the time lag between receiving the POs and ordinary cash flows to one month $(g=1)$.

Model of impairment losses The present value of impairment losses is calculated using the net present value of operating earnings as follows:

$$
\begin{aligned}
I_{t} & =\min \left(\tilde{V}_{t}-\tilde{V}_{0}, 0\right), \\
\tilde{V}_{t} & =\sum_{s=t}^{\infty} \frac{\mathbb{E}^{\mathbb{P}}\left[\tilde{P}_{s} \mid \mathcal{F}_{t}\right]}{(1+r)^{s-t}}
\end{aligned}
$$

\footnotetext{
${ }^{12}$ Using asset correlation is desirable, but we employed stock correlation for data restriction.

${ }^{13}$ A test for spurious regression is desirable. However, we did not check spurious regression because of the insufficient sample size.

14 The unit of the estimated parameter value is Yen.
} 
Here, $\tilde{P}_{t}$ is operating earnings. Constant $r$ is the firm's weighted average cost of capital (WACC). Operating earnings are given by

$$
\tilde{P}_{t}=S_{t}-\tilde{C}_{t}
$$

where operating costs $\tilde{C}_{t}=\tilde{f}\left(\left\{O_{t-g}^{i}\right\}_{i \in \mathcal{I}}\right)$ with the following linear operating cost function:

$$
\tilde{f}\left(\left\{O_{t-g}^{i}\right\}_{i \in \mathcal{I}}\right)=\tilde{a} \sum_{i=1}^{I}\left(O_{t-g}^{i} 1_{\left\{t<T_{i}\right\}}\right)+\tilde{b} .
$$

The estimation procedures for the operating cost function are similar to the case of ordinary cash flow functions. To estimate the parameters of the operating costs function, we use the historical annual PO volumes and operating costs on $\mathrm{P} / \mathrm{L}$. We execute linear regression of realized operating costs by employing annual sales as explanatory variables. The coefficients obtained by linear regression are annually based values; then, we transform the monthly based values. The obtained coefficients of ordinary cash flow function are $\tilde{a}=0.904$ and $\tilde{b}=8.08 \times 10^{8}$.

When calculating $\tilde{V}_{t}$, we set the end of the forecast period of operating earnings as the $M$-th time point from an evaluating time point. Then, we obtain net present value of operating earnings after the end of the forecast period with the terminal value. Thus, the net present value of operating earnings is the sum of the present value of operating earnings during the forecast period and the terminal value:

$$
\tilde{V}_{t}=\sum_{s=t}^{M-1} \frac{\mathbb{E}^{\mathbb{P}}\left[\tilde{P}_{s} \mid \mathcal{F}_{t}\right]}{(1+r)^{s-t}}+\frac{\mathbb{E}^{\mathbb{P}}\left[\tilde{P}_{M} \mid \mathcal{F}_{t}\right]}{r(1+r)^{M-t-1}} .
$$

We calculate the corporate value of profits by setting the end of the forecast period to five years $(M=60)$.

Then, the adjusted impairment losses are obtained by

$$
\bar{I}_{t}=I_{t} \times \frac{\bar{V}_{0}}{\tilde{V}_{0}}
$$

where $\tilde{V}_{0}$ is the book value of operating profit and losses.

We obtain the WACC for Kojima Industries Corporation using the capital asset pricing model (CAPM). To obtain the WACC, we calculate the cost of equity by

$$
r_{s}=r_{f}+\beta\left(r_{m}-r_{f}\right)
$$

where $r_{f}$ is the risk-free rate, $r_{m}$ is market return, and $\beta$ is the levered beta of Kojima Industries Corporation. To obtain the levered beta, we first obtain the unlevered beta by calculating the averages of the unlevered beta of listed firms belonging to the transportation equipment sector. Then, we calculate the levered beta with the 
estimated unlevered beta and capital weights of Kojima Industries Corporation. We set the risk premium $r_{m}-r_{f}$ to $4 \%$. Then, we obtain the cost of debt $r_{D}$ from the amount of interest-bearing liabilities and the amount of interest paid. With the estimated cost of equity and cost of debt, we calculate the WACC as follows:

$$
r=\frac{H}{H+D} r_{s}+(1-G) \frac{D}{H+D} r_{D}
$$

Here, variable $H$ is the book value of net assets and $D$ is the book value of liabilities. The risk-free rate $r_{f}$ is obtained from yields of 10 -year government bonds. We execute these procedures on a daily and average per month basis to obtain monthly WACC. The range of obtained WACC is $3.52 \% \sim 3.84 \%$. We set $G=0.4$.

Finally, cumulative EBT is given by $E B T_{t}=P_{t}+\bar{I}_{t}$.

\section{Monte carlo simulation}

Using the settings above, we simulate the future PO volumes, calculate corporate values and obtain the probability of default (PD) of Kojima Industries Corporation. The simulation is executed under a monthly time-span with 100,000 trials. The number of default trials in which the net capital becomes negative is counted, and PDs are obtained by the ratio of the number of default trials to the number of all trials.

\section{References}

Genser, Michael, A structural framework for the pricing of corporate securities, Springer, 2006.

Goldstein, Robert, Nengjiu Ju, and Hayne Leland, "An EBIT-Based Model of Dynamic Capital Structure," Journal of Business, 74(4), 2001, pp.483-512.

Merton, Robert, "On the pricing of corporate debt," Journal of Finance, 29(2), 1974, pp.449-470.

Udell, Gregory, Asset-based finance, The Commercial Finance Association, 2004. 